\title{
FUNCIONES NORMATIVAS Y VOLUNTAD DE SIGNO
}

ROBERTO J, VERNENGO

Universidad Autónoma Metropolitana, México

1. Norma y voluntad. Es una vieja tradición del pensamiento iusfilosófico el relacionar de alguna manera (al punto de identificarlos) la voluntad con el derecho. Cuando, con la dogmática del siglo XIX, el derecho fue visto como un conjunto normativo de características específicas, el elemento simple, la norma de derecho fue considerada como la expresión de un acto de voluntad. $Y$, más concretamente, como la expresión de una orden o mandato. De ahí el auge de las denominadas teorías imperativistas en la teoría general del derecho, según las cuales, para decirlo con las palabras de uno de sus representantes magnos, Austin, el derecho era visto como órdenes del soberano.1 En el terreno filosófico, Hegel, nada menos (sin que ello significara sostener una tesis demasiado novedosa u original), también apuntaba a la voluntad como el lugar (Stelle) en que el derecho radica. 2

Sin embargo y curiosamente, buena parte de los esfuerzos de la teoría jurídica, en la primera mitad de nuestro siglo, consistieron en una esforzada tentativa por desprenderse de los presupuestos imperativistas que, por lo común, eran considerados como una suerte de reducción, expresa o tácita, de los fenómenos jurídicos a datos psicológicos. La voluntad, este misterioso nombre de una de las facultades del alma $y$, por ende, uno de los ingredientes esenciales del ser del hombre, era reducido a fenómeno psicológico de los que se ocupaba la incipiente psicología empírica. Parecía claro a los juristas que me refiero, que la ciencia del derecho nada tenía que hacer con una psicología empírica ni con sus métodos. En algún

1 J. Austin, Lectures on Jurisprudence, lect. 1.

2 G.W. Hegel, Rech tsphilosophie, parágrafo 4. 
momento se creyó que el imperativismo, como ejemplo de una incursión de la psicología en la jurisprudencia, había quedado definitivamente descartado. Pese a ello la terminología voluntarista, el discurso sobre el querer y la voluntad, que se remonta a la jurisprudencia romana, continuó formando parte del vocabulario habitual de los juristas.

Es verdad que múltiples veces se ha manifestado, por juristas preocupados por los problemas más diversos, que la voluntad jurídica, que se nos aparece al más alto nivel político como voluntad del constituyente o como voluntad del legislador, hasta la voluntad más modesta del simple contratante particular, no podía identificarse con ninguna voluntad psicológica real. Pero sucede, paradójicamente, que la psicología contemporánea, habiendo quizás tomado su distancia de la venerable doctrina referente a las facultades del alma y habiendo producido su propio arsenal de conceptos teóricos, también se ha desentendido del estudio de tal supuesta facultad, la voluntad, relegándola a la problemática de la especulación metafísica tradicional que largamente se había ocupado de ella. ${ }^{3}$ La teoría del derecho, renuente en nuestros tiempos a fundarse en creencias metafísicas e imposibilitada de buscar recursos en la ciencia psicológica moderna, echó mano de diversos subterfugios: la voluntad dejaba de ser dato real de ningún tipo, para convertirse en una ficción, en una voluntad ficticia, ya no empírica, como caracterización ontológica de los actos sociales productores de normas. 4 Tuvo, pues, que prescindir de ellos como pseudoconceptos carentes de referencia, o redefinir las variadas voluntades de que hacía mención el discurso de la jurisprudencia y de la teoría del Estado: poco quedó, por ejemplo, de la tradicional voluntad del Estado, aceptada ahora a lo sumo como una metáfora. Pero el análisis reductivo de semejante noción sirvió para esclarecer muchas dificultades teóricas del lenguaje de la jurisprudencia y para destacar, como

3 Cf. inter alia y como representante de una tendencia importante de la psicología contemporánea, B.F. Skinner, About Behaviorism, New York, Vintage Books, 1976.

4 Asi en Kelsen y en su interpretación tardia de.la norma fundamental (Grund. norm). 
nunca antes se lo había hecho, la útil ambigüedad ideológica con que pueden ser empleados.

Resulta ahora, sorprendentemente, que disciplinas recientes, como las lógicas normativas que comenzaron a desarrollarse a partir de la década del 50, luego de un largo período en que se ocuparon de desentrañar las relaciones de compatibilidad y de inferencia lógicas posibles entre normas o entre enunciados normativos, como si normas o enunciados normativos fueran análogos a las proposiciones $u$ otros entes abstractos o ideales con que se ocupaban algunas lógicas tradicionales, vuelven a preocuparse por la relación entre tales objetos, las normas y los enunciados normativos, y los actos de voluntad.5 Como si se pretendiera reconstruir aquella logic of the will que anunció Bentham, de alguna manera se tiene presente la circunstancia de que una norma (en cuanto enunciado gramatical de cierto tipo que funciona en determinados contextos) no puede ser enteramente entendida sin ponerla en relación con alguna acción de cuya regulación se trata, en cuanto constituye su contenido. 6 Frente a una actitud ascépticamente formal en relación con los enunciados normativos, a una consideración puramente sintáctica de los mismos, se atiende ahora a los ingredientes semánticos que contienen y a las funciones que desempeñan en diversos contextos de uso. Pareciera que son los aspectos ilocucionarios los propios de todo enunciado que pueda considerarse una norma, en el sentido que interesa a los juristas y moralistas. La eliminación de la supuesta falacia naturalista, que el imperativismo habría introducido en la teoría del derecho, no ha sido efectivamente lograda -cabe creer-, y, por consiguiente, la relación entre acto de voluntad y norma (o enunciado normativo) sigue siendo un problema importante del pensamiento iusfilosófico. Propongo, en las páginas que siguen, algunas aproximaciones

5 Cf, ahora C. Alchourrón y E. Bulygin, Sobre la existencia de las normas jurídicas (1979) y The Expressive Conception of Norms (en R. Hilpinen, "New Studies in Deontic Logic", Reidel, 1981).

6 Cf. G. von Wright, On the Logic of Norms and Actions (en R. Hilpinen, op. cit.); tesis semejante ya había sido discutida por Kelsen, al tratar de la relación entre norma y conducta humana: cf. Reine Rechtslehre, ed., Wien: F. Deuticke, 1960 , parágrafo 14 y ss. 
con conceptos que la filosofía hace tiempo ha desatendido, pero cuyo valor explicativo e histórico me parece no debiera ser descartado.

2. Voluntad y funciones normativas. Quizás la aceptación no cuestionada que reciben enunciados éticos de gran generalidad -como el mandamiento que prohibe matar a otro ser humano- influyó para que se prestara atención preferente a los aspectos lógico-sintácticos de tal tipo de norma; se trata, al fin y al cabo, de una prescripción que responde a una pretensión moral prima facie válida en cualquier tiempo y lugar y en cuyo respecto no interesa mucho quién la hubiera instituído o quiénes fueran los que debieran acatarla. Las normas éticas universales y, por extensión, las jurídicas, serían objetos lógicos abstractos, idénticos o análogos a los que ocupan a la lógica formal o a la gramática pura. El jurista sabe, sin embargo, que enunciados de tal aparente simplicidad no pueden ser cntendidos, en rigor y sin más, como normas jurídicas, mientras que de algún modo no se consiga especificar otra serie de elementos que pueden, quizás, hacer de ese muñón prescriptivo una norma jurídica positiva y válida: ¿quién ordenó tal cosa?; ¿cuándo y dónde rige prohibición pareja?; ¿desde cuándo y hasta cuándo debe estimarse que la interdicción debe ser acatada?; ¿es esa prohibición compatible con otras reglas, principios y normas que sí consideramos derecho válido? Estas preguntas y otras, requieren de respuestas para que el simple mandamiento, no matar, por moralmente evidente que nos parezca, adquiera las características necesarias de una norma que un órgano estatal, por ejemplo, un juez, o una autoridad teórica jurisprudencial, puedan invocar como norma válida. Dado que los jueces y los jurisconsultos no se ocupan, en principio, de preceptos que puedan parecer moralmente evidentes, sino principalmente de normas válidas creadas por órganos sociales.

En el estudio, pues, de las normas existentes de una sociedad jurídicamente organizada, es cuestión crucial la forma de su instauración o creación. Averigüar quién introduce, al estatuírla, una norma en un sistema social es pregunta que requiere de un procedimiento para darle una respuesta categó- 
rica. Esa respuesta es condición para que los órganos jurisdiccionales puedan actuar legítimamente. Ante la norma cuyo pedigree no pudiera determinarse, titubearíamos en hablar de derecho positivo. Más aún, corresponde señalar que también quienes invocan el derecho natural deben ocuparse en verificar si la norma (no positiva) que pretenden aplicar realmente expresa la vis insita en la naturaleza de las cosas, vis que, claro está, no es fuerza físico-mecánica alguna, sino una suerte de fuerza o voluntad metafísica supuesta en las cosas y que dedetermina no sólo el comportamiento de las cosas mismas, sino la conducta de los hombres al respecto.

Ahora bien, parece notorio que no hay acto volitivo sin un sujeto psicológico que lo lleve a cabo. Así como en el kantismo todo enunciado teórica implica la tesis de un cogitum del ego trascendental, en toda acción legislativa, en todo acto de normar, debe asumirse como presupuesto el velle de algún sujeto práctico. De ahí la repetida tesis que no admite la existencia de un imperativo sin un imperator, tesis que acepta diversas lecturas y diversos niveles de confusion. Esta tesis haría, en una interpretación empírica, a la cuestión del origen de un precepto jurídico; no, en cambio, a la cuestión de la obligatoreidad de su aplicación consecuente. El jurista positivista, empero, piensa que la verificación del acto empírico de creación es condición necesaria para que el enunciado normativo que recibe del legislador pueda ser obligatorio: es éste uno de los principios mismos del positivismo. El jurista, circunscripto sea al estudio, sea a la aplicación del derecho positivo - y no de otras normas, en principio- necesita contar con información referente al concreto acto legislativo en que se haya instaurado la norma. De no poder establecerse la relación con esta acción concreta de un imperator, con la voluntad del legislador, no habría derecho positivo alguno que aplicar; cuando, por tratarse de normas consuetudinarias, tal legislador y tales actos faltan, el jurista debe recurrir a alguna ficción que le permita seguir aplicando el modelo del acto volitivo y su norma resultante.

Pero aun en el caso de legisladores concretos, del acto creador que produzcan no se sigue que la voluntad legislativa, su- 
puestamente dada en ese acto, deba mantenerse de alguna suerte mágica para asegurar la prolongada validez temporal de la norma producida; por el contrario, bien puede legislador y su voluntad (real o imaginaria) desaparecer, sin que la norma pierda su fuerza obligatoria. Es decir, para que continúe funcionando como imperativo. El acto de voluntad es un presupuesto del momento inicial de vigencia de la norma, de su introducción en un orden jurídico, pero no de la duración efectiva de su validez. Se supone, pues, que el legislador no sólo quiere que una norma ingrese en el orden jurídico, sino que también determina $a b$ initio la extensión de su ámbito de validez temporal. Estas diversas posibilidades son a veces atendidas a veces descartadas como irrelevantes por la teoría del derecho, que sólo recientemente se ha hecho cargo del problema de la compleja relación entre la duración de la validez de una norma y la duración global del sistema normativo que integra. ${ }^{7}$ Si con la teoría corriente sobre usos y funciones del lenguaje, se hace hincapié en que un enunciado cualquiera sólo puede funcionar como norma en un contexto ilocucionario específico (en el cual es entendido, por ejemplo, como el instrumento lingü ístico que transmite una orden), ello requiere que entre el emisor y el receptor del mensaje lingü ístico se constituya una relación social, diversamente denominada: "imperativo", "orden", "mandato" (o Gebot, Befehl, mand, etc.) que permita la constitución de la función ilocucionaria imperativa.

3. El imperativismo en Kelsen. Es interesante e importante perseguir la evolución del modelo imperativista en la teoría del derecho kelseniana, dado el papel central que a la misma corresponde en la teoría del derecho de nuestro siglo. Cierto es que en su obra publicada en vida -no así, en la póstuma-, Kelsen no llega a asumir plenamente los logros de las lógicas normativas desarrolladas a partir de 1950, ni tampoco los análisis de la filosofía del lenguaje que se remontan al segundo Wittgenstein y a J.L. Austin. Corresponde destacar también

7 Cf. J. Raz, The Concept of a Legal System (Oxford U.P., 1970) y, más recientemente, E. Bulyingin, Time and Validity, en S: Deontic Logic, ed. A. Martino, Holland: Reidel, 1982. 
que tanto los lógicos que se han ocupado de las lógicas modales deónticas y normativas (en sus múltiples avatares), así como los filósofos del lenguaje y gramáticos interesados en la filosofía, han tenido que tomar en cuenta diferenciaciones y matices que los juristas tradicionalmente atendían. De ahí que una fuente importante de repertorios de actos lingü ísticos derive de la literatura jurídica.

En Kclsen, en todo caso, es tesis expresa en la versión definitiva de la Reine Rechtslehre 8 que.las normas, sea cual fuere su aspecto lógico-gramatical y su función efectiva en el acto de comunicación -se dan en relacićn esencial con actos de voluntad: constituyen ellas el sentido (Sinn) de los actos de voluntad de quien las instaura.

Los actos de voluntad son momentos discernibles en el curso de la actividad psicológica real de seres humanos concretos: el acto de voluntad es un Seinstatsache, un hecho empírico efectivo, un dato de la realidad. Qué sea, en cambio, el sentido (Sinn) de esos hechos, es cosa que no tiene igual precisión ontológica en Kelsen, dado que en este autor no aparece una reflexión suficiente sobre la relación semántica específica de los enunciados normativos: se refieren a la conducta, pero simultáncamente son el sentido de la voluntad del órgano normador. El sentido no se identifica con el contenido significativo del enunciado normativo, sino que la norma otorga sentido a una acción empírica. Todo ello, por cierto, admite diversas lecturas c interpretaciones aun en el pensamiento filosófico con el que Kelscn era familiar. Opalek, por ejemplo, al efectuar el balance de estas ideas, considera que se trata de una tesis de "evidente origen neokantiano: se trata aquí de un sentido deóntico (Soll-Sinn) supraempírico de los hechos cmpíricos, que o bien -si se quiere ser consecuente - tiene que ser presupuesto como inmanentc a esos hechos, o bien significa un paso no fundado de lo empírico a lo supraempírico".9

Esta conclusión adquiere mayor asidero si nos remitimos a la obra póstuma de Kelsen, la Allgemeine Theorie der Nor-

8 Existe traduceión castellana, "Teoría pura del Derecho", UNAM, 1979.

9 K. Opalek, Überlegungen zu H. Kelsens 'Allgemeine Theorie der Normen', Wien: Manz, 1980, p. 22. 
men. 10 Las normas -en sus diversas formas superficiales de darse, como órdenes, mandamientos, prohibiciones, autorizaciones, delegaciones, etc., asi como en las diversas funciones que cumplen en la relación comunicativa: obligar, prohibir, delegar, facultar, derogar, siguen siendo vistas como sentidos de actos de voluntad. Precepto, regla, norma, o cualquier otra formulación lingüística que se adopte, no constituyen sino "la expresión verbal" del sentido del acto de voluntad instaurador. También constituyen, corresponde agregar, la expresión transmisora al receptor de la función normativa en juego.11 Kelsen insiste en que el indicador verbal de todas las funciones normativas - el verbo sollen - debe ser interpretado, al nivel de la teoría general de las normas, como representante común de todos los modos deónticos.

Sin embargo, el vocablo no adquiere por eso una función puramente lógica, dado que Kelsen insiste en que se trata de un término categoremático: el sollen expresa el sentido de un querer, de un acto de voluntad.12 Tendríamos así que, en los enunciados normativos, el conjunto de sus elementos expresa el sentido de un acto de voluntad; a su vez, uno de los términos integrantes del enunciado, el ingrediente verbal modal deóntico, expresa la relación común que tiene el enunciado en que figura con un acto de voluntad. Es decir: el sollen, diríamos gramaticalmente, transforma un enunciado declarativo en un enunciado prescriptivo. Se trataría de un marcador de una transformación, cuya efectividad sólo puede acreditarse en algún contexto pragmático. ${ }^{13}$

La voluntad ya no es ahora, como lo era en la Reine Rechtslehre de 1960, en hecho empírico, un Seins-Tatsache. Más aun, el sentido del acto de voluntad, piensa el Kelsen tard ío, tampoco es susceptible de expresarse enunciativamente. Veamos los textos: en la conducta propia (inclusive al nivel más elemental de un simple movimiento muscular), la voluntad no se identifica con "el impulso que conduce a la innervación del múscu-

$10 \mathrm{H}$. Kelsen, Allgemeine Theorie der Normen. Wien: Manz, 1979.

11 Op. cit., p. 2, cap. I, iii).

12 Op. cit., p. 77, cap. 25, II).

13 Op. cit., p. 25, cap. 9, I). 
lo", impulso nervioso que sí constituye la causa inmediata del movimiento muscular. ${ }^{14} \mathrm{El}$ sujeto activo, cree Kelsen, distingue en "forma conscientemente inmediata" sus movimientos voluntarios de los involuntarios; con esa diferenciación inmediata en la conciencia, el sujeto actuante adopta la tesis de que el movimiento corporal considerado voluntario, no sólo tiene como causa inmediata al impulso nervioso que sea, sino que considera que aquel movimiento es provocado casualmente por "un acto de voluntad inmediatamente antecedente".15 Sólo que ese acto de voluntad antecedente no es susceptible de verificación`alguna: "Tal acto de voluntad no es determinable (festellbar) por introspección (Selbstbeobachtung)".16 A fortiori, tampoco ningún observador externo podría comprobar la existencia de un acto de voluntad, precedente en el sujeto activo, a su movimiento muscular. El carácter de acto voluntario, no determinable ni externa ni introsplectivamente, sólo sería inferible "como algo que se distingue de mi pensar y de mi sentir, y que justamente por ello denomino 'querer' ".17

Parece claro que el acto de voluntad ha perdido su condición de dato psicológico empírico, de hecho verificable, de hecho en el mundo de la realidad (Seins-Tatsache), y ha pasado a ser algo que ni siquiera el sujeto activo puede identificar en actitud introspectiva. A lo sumo, sólo puede inferirlo en cuanto diferente del pensar y del sentir. Nuevamente aquí la voluntad se reduce a una de las clásicas facultades del alma y es definida por exclusión de las otras. Pero, claro está, la voluntad como facultad del alma no es un dato psicológico empírico, sino un ente metafísico o, si se quiere, en una versión más modesta, una ficción o una construcción teórica.

4. Voluntad y caracteres deónticos. En esta entidad metafísica, la voluntad no verificable empíricamente, residiría la actividad productora de normas. Dado que no cabe, por definición, acceso experimental a la misma, resulta que todo el

14 Op. cit., p. 24, cap. 9, I).

15 Ibidem.

16 Op. cit., p. 24, cap. 9, I).

17 Op. cit., p. 25, cap. 9, I). 
proceso volitivo de producción de normas solo puede presuponerse a partir de las expresiones verbales en que el imperar, el prohibir, el autorizar o el derogar se manifiestan. Imperar, prohibir, etc., son acciones visibles de un agente; $\mathbf{o}$, mejor dicho, los movimientos externos de un sujeto admiten ser interpretados como actos de prohibir, imperar, autorizar, etc., a través de un enunciado normativo que así los caracterice.

Ahora bien, no hay expresión verbal comprensiva del sentido de un acto de voluntad instaurador de una norma que no aparezca especificado en una función. Pero una función es una acción, como movimiento corporal de algún agente, con un sentido normativamente asignado. Vale decir que, en términos generales, no hay actos de voluntad genéricos cuya función fuera producir las correspondientes normas (al imperar, una norma que obliga ; al prohibir, una que obliga a omitir, etc.) sino que sólo contamos, como punto de partida, con normas que otorgan algún sentido normativo a actos del agente. Estos actos son interpretados como la manifestación externa de una voluntad antecedente, voluntad a la que se le atribuye ser la portadora del sentido deóntico que se asigna a la acción. Sólo tenemos, pues, normas que simultáneamente expresan cuál sea la función normativa que se atribuye a la voluntad imperante o prohibitiva, $y$ otorgan a la acción externa del agente el sentido que se supone esa voluntad antecedente le confería. Las normas contienen, por un lado, una formulación verbal de cuál es la función normativa que se pretende ejercer (el cariz ilocucionario), y, por el otro, algún indicador modal genérico (algún in dicador gramatical deóntico) que transmite el sentido de un "deber querido", de un sollen cuya contrapartida sería un presupuesto y necesario wollen.

Las funciones normativas son taxativamente enumeradas en la Allgemeine Theorie: se trata de las funciones de ordenar y prohibir, de permitir y facultar (autorizar) y la de derogar.18 El origen de estas funciones es fácil de rastrear en las regulaciones (Regelung), positivas y negativas, indicadas en la Reine.

$18 O p$. cit., pp. 25 y ss. 
Rechtslehre de 1960,19 en páginas cuya interpretación cabal ha sido tan difícil hasta ahora. Sea ello como fuere, Kelsen insiste en que las funciones de ordenar, prohibir, permitir y autorizar constituyen otros tantos sentidos posibles - de sentidos normativos posibles-, de actos de voluntad. O mejor, son el sentido asignable, por el pensamiento normativo, a acciones externas de algún agente cuya voluntad antecedente, no empíricamente verificable, constituiría el presupucsto unitario de un ego práctico que así se manifiesta fenoménicamente. (Cabe señalar que la derogación presenta peculiaridades específicas, dado que, como Kelsen apunta, no se trataría de un acto de voluntad dirigido a orientar la conducta ajena.)

Ahora bien, parece notorio que cualquier norma, sea cual fuere su función, no tiene voluntad alguna; la voluntad, de existir tal cosa, es algo propio del sujeto agente, una facultad de su alma. La norma, reconoce Kelsen, no "quiere nada", ni tampoco, en rigor, quiere nada específico el indicador verbal (el verbo sollen, por lo común) que el enunciado normativo contiene para poder ser entendido como expresión o realización de una función normativa. 20

La voluntad expresada genéricamente en el verbo modal sollen, la voluntad expresada diferenciadamente en las funciones (ilocucionarias) normativas, la voluntad atribuída al imperator que quiere que las normas jurídicas valgan, todas estas voluntades no son otra cosa que el residuo, en la teoría del derecho contemporánea, de la voluntad o vis que una pertinaz y prestigiosa tradición metafísica proclama toda vez que se trata de caracterizar ontológicamente y en última instancia a un objeto científicamente determinable. Las funciones normativas de la Allgemeine Theorie reflejan, además, las modalidades con que esa omnipresente voluntad metafísica se manifestaba en la terminología de la escolástica clásica.

4. Funciones normativas y signa voluntatis. En este caso, que podemos aceptar representado aqui por el Aquinate, rige un cierto cuerpo de creencias sobre la constitución metafísica del hombre y, en especial, sobre las facultades de su alma.

19 Reine Rechtslehre, op. cit., p. 15.

20 Allgemeine Theorie, p. 134, cap. 43. 
Tomás también acepta que el conocimiento $-\mathrm{y}$ se trata de una tesis central en el pensamiento metafísico de Occidente, tal como lo vemos luego expresarse, por ejemplo, en Kantno es facultad que permita un acceso a las cosas tal como son en sí mismas: el conocimiento (la ciencia que se tiene de las cosas) es siempre relativo al sujeto cognoscente; a la facultad intelectual o cognoscitiva las cosas se dan tal como aparecen al sujeto: secundum quod sunt in sciente; la voluntad, en cambio, que toca a las cosas mismas: comparatur ad res secundum quod sunt in seipsis.21 De ahí que el ser perfecto, Dios, es aquél en que intelecto y voluntad van juntos; en Dios, intelligere est suum esse, ita suum velle,22 el ser divino es su conocer, así como su querer. En el ser creado, imperfecto, como en el caso del hombre, intelecto y voluntad no se complican y confunden, aún cuando el contar con el intelecto implique, en el ser racional, el contar también con la voluntad, por cuanto in quolibet habente intellectum, est voluntas. ${ }^{23}$

$\mathrm{Y}$, tanto en el ser creador perfecto, Dios, como en el ser creado imperfecto, el hombre, la característica de ser operante, activo, hacedor, es atribuída a esa fuerza metafísica que denominamos "voluntad".

Por eso dice Tomás que la voluntad divina, que en la esencia de Dios se confunde con los otros atributos que religiosa o dogmáticamente se le atribuyen, tiene que ser entendida metaphorice, metafóricamente cuando se trata luego de comprender el funcionamiento de la voluntad humana, como causa determinante del hacer u omitir de un sujeto empírico y, sobre todo, cuando se trata de especificarla en su función de determinante del hacer u omitir ajenos. En esta última función, necesitamos que la voluntad suprema metafísica, radicada en la divinidad, o metafísicamente presupuesta por participación en el ser creado, se manifieste fenoménic amente. Continuando con una terminología tradicional, 'Tomás denomina a esa voluntad fenoménicamente expresaúa signa voluntatis: signos o

\footnotetext{
21 Summa Theol. I, q. 19, a 3 ).

2 I, q. 19, a. 1.

23 Ibidem.
} 
señales volitivos. $24 \mathrm{El}$ instituir una norma -el hecho real de que alguien formule un precepto de algo: cum aliquis praecipit aliquid- es señal de que se quiere algo, de que hay detrás del signo una voluntad operante. 25

Si nos reducimos al nivel empírico, la voluntad puede identificarse con las señales que la exteriorizan, con los signos que la manifiestan: eo quod ipsum signum voluntatis voluntas dicitur ("por cuya razón, puede llamarse voluntad al signo mismo volitivo"). 26

Ahora bien, ¿cuáles serían los signos habituales con que la voluntad (divina o humana) se manifiesta?; el artículo 12 , de la I, q. 19 de la Summa los enumera. Coinciden, en una interesante medida, con las funciones normativas que también Kelsen, en sus obras tardías, atribuye a sendos actos del mítico sujeto volente cuya mítica voluntad produce normas. Así, en el Aquinate, la conducta ajena es determinada recurriendo a actos de prescribir (praecipiendo) y de prohibir (prohibendo): son éstas las formas significativas de ordenar que otro haga $u$ omita algo. Pero también, advierte el teólogo, la eliminación de una prohibición es una manera de determinar conductas: el modo de la determinación (su signo o señal) es el de la permisión. Prescripción, prohibición y permisión son las señales volitivas correspondientes a las funciones normativas de ordenar, prohibir y permitir. En tanto signos o señales con datos empíricos verificables; la voluntad que a través de ellos se manifiesta no lo es. La voluntad es el objeto metafísico del que se suponen tales signos emanan, como su expresión visible.

La jurisprudencia se ha interesado sobre todo en los signos voluntatis no divinos, aunque la voluntad supuesta tampoco sea normalmente accesible a experiencia alguna. $A$ veces, los juristas invocan una voluntad casi divina: la voluntad del Estado o de la Nación o del pueblo. Es decir, la jurisprudencia también ha atribuído a las manifestaciones externas, consistentes en las denominadas funciones normativas, un sustrato

24 Cf. I, q. 19, a. 11 y 12.

251, q. 19, a. 11 .

26 Ibidem. 
metafísico más allá de toda experiencia empírica. De ahí que Kelsen tuviera que recurrir al absurdo engendro de una voluntad ficticia, en lugar de admitir la condición de presupuesto que efectivamente da la jurisprudencia a esa construcción denominada "voluntad".

Es algo bastante conocido y que estas páginas insisten en recordar, que las ciencias actuales conservan, bajo distintos rótulos, presupuestos derivados de formas anteriores del pensamiento metafísico, presupuestos cuyo carácter y origen no son cabalmente entendidos. En la ciencia del derecho, destacadamente, la voluntad y sus diversas formas y avatares constituyen este incólume presupuesto metafísico que, como se ha visto, aún aceptan, tácita o expresamente, los positivistas más aguerridos y preclaros. Quizás no pueda ser de otra manera y sea inútil sorprenderse de la terca sobrevivencia de tales nociones. Nos sorprendemos ante lo que nos maravilla: ya Nietzsche destacó que toda vez que pensamos a las cosas (a los entes) como acciones, o como resultado de acciones (de un hacer), tenemos que buscarle un fundamento que nos aparezca como milagroso y maravilloso (wunderlich). ${ }^{27}$ Que, de pronto, la emisión de una norma cambie la vida de algunos de nosotros también tiene que ser explicado recurriendo a una causa maravillosa: los juristas echan aún hoy mano de la voluntad cuando quieren dar una explicación última. No se sorprendan, entonces, que aún hoy la ciencia del derecho actual continúe invocando esa instancia final: la voluntad como fuente o causa de los fenómenos por los que se interesa.

27 F. Nietzsche, Jenseits von Gut und Bösex, 19. 
SUMMARY

Legal philosophers and logicians study problems related to the syntactical and semantical aspects of norms, without worrying about the ilocutionary aspects of their use. With Kelsen's posthumous work, the Allgemeine Theorie der Normen, and the new preoccupations of deontic logicians, it seems that what is called the "normative functions" of norms are becoming a central point of the discussions between logicians and philosophers of law and moralists.

Traditionally, the ilocutionary aspects of norms has been construed as the question of the empirical manifestation of the will, as it is suppossed that every norm expresses somebody's will. Nevertheless, that thesis -although traditional in legal and moral thought-implies some metaphysical presuppositions concerning the ontological status of what is called "thc will" which must be brought to light if jurisprudence is going to attain a modern scientific approach. In Kelsen"s work it seems clear that the relationship between das Sollen and das Wollen is where that old metaphysical idea regains strength.

It can be found in Thomas Aquinas - and the classical scholastics- a sort of theory on the empirical expression of acts of will, know as signa voluntatis, which keeps close and analogy with the normative functions of modern jurisprudence. Perhaps the theory of positive law, as manifestation of signa voluntatis, would establish a bridge between modern legal positivism and some forms of classiçal natural law. 